\title{
Gênero, raça, desigualdades e políticas de ação afirmativa no ensino superior
}

Gender, race, inequalities and affirmative action policies in higher education

No que diz respeito à desigualdade racial no ensino superior e às políticas de ação afirmativa nessa área, tanto o debate público quanto a literatura acadêmica tratam, principalmente, da situação dos estudantes. A existência, atualmente, de dados disponíveis sobre a composição da população de estudantes segundo a cor favoreceu a realização de estudos sobre a desigualdade racial na educação, cujos resultados mostram que as desvantagens dos estudantes negros em relação aos brancos crescem a partir do ensino médio e chegam ao ápice no ensino superior e pós-graduação (Silva, 2013; Charão, 2011; Paixão et al., 2010). As demandas antigas e recentes das organizações antirracistas por mais acesso às oportunidades educacionais, bem como o maior apelo do argumento em favor dos estudantes diante da opinião pública também ajudam a explicar por que os estudantes têm sido os principais focos das pesquisas e experiências brasileiras recentes com as políticas de ação afirmativa (Santos, 2012).

É inegável que a alteração das regras para o acesso dos estudantes aos cursos de graduação, que resultaram em aumento proporcional de estudantes negros através das políticas de ação afirmativa, foi uma mudança institucional importante, pois passou a garantir a esse segmento o acesso a oportunidades sociais que antes lhe eram restritas ou inexistentes (Santos, 2013; Feres Jr. e Zoninsein, 2008; Barreto, 2008; Brandão, 2007). Mas fica

É professora do Departamento de Sociologia da Universidade Federal da Bahia (UFBA). E-mail: <paulacba@ufba.br>. 
a pergunta sobre se, e quanto, as Instituições de Ensino Superior (IES) que adotaram tais políticas estão se transformando, de maneira mais geral, no sentido de promover a igualdade racial, considerando a interface não apenas com a classe social, mas também com o gênero.

Para abordar esse tema, é preciso não restringir a análise aos beneficiários das políticas de ação afirmativa adotadas, mas ampliar o enfoque para incluir outra categoria importante na comunidade universitária, ou seja, aquela formada por professores e professoras, bem como para incluir os currículos e as relações construídas no cotidiano. Em outras palavras, se faz necessário pensar as instituições de ensino superior de uma maneira mais global, e considerar em sua análise a articulação entre dimensões distintas das desigualdades, com destaque para raça, classe e gênero.

Em relação à situação docente, Carvalho (2005-2006) já destacou que nas IES brasileiras há redutos formados quase integralmente por professores brancos, onde os poucos negros existentes são isolados e enfrentam várias formas de estigmatização no cotidiano. No entanto, esse tema ainda merece ser objeto de estudos que forneçam evidências empíricas sobre a composição segundo a cor do corpo docente, e sobre as experiências profissionais e pessoais dos docentes, em especial, dos homens e mulheres negros(as) que construíram, em diferentes momentos, suas carreiras acadêmicas nessas instituições (Santos, 2007).

Com a continuidade da realização de estudos sobre a desigualdade racial no ensino superior, e dez anos depois das primeiras iniciativas de criação das políticas de ação afirmativa, estão surgindo outras demandas quando se trata de promover a igualdade racial nas IES, e outros temas de pesquisa, com destaque para a criação de espaços institucionais e de projetos antirracistas e antissexistas, a inovação nos currículos e a situação dos docentes. Em termos teóricos, a preocupação com a interface entre classe, gênero e raça cresceu na pesquisa sobre desigualdade, incentivada, por exemplo, pelos estudos que utilizam a abordagem interseccional.

As categorias de articulação e as interseccionalidades estão cada vez mais presentes no debate teórico recente, visando ampliar a compreensão sobre os modos como múltiplas diferenciações que permeiam o social articulam-se a gênero (Piscitelli, 2008). Na revisão da literatura sobre o tema, Piscitelli destaca que a utilização desses conceitos foi precedida por inúmeras formulações críticas aos usos essencialistas dos conceitos de sexo e gênero em 
distintas correntes do feminismo, que destacaram a heterogeneidade interna da categoria "mulher" e os limites do binarismo masculino/feminino nas relações de gênero. Segundo Piscitelli, os conceitos de categorias de articulação e de interseccionalidade não são utilizados de maneira homogênea entre as autoras que se tornaram mais influentes na discussão sobre gênero.

Creenshaw (2002) analisa a forma pela qual o racismo, o patriarcalismo, a opressão de classe e outros sistemas discriminatórios criam desigualdades básicas que estruturam as posições relativas de mulheres, raças, etnias e classes, entre outras. O interesse da autora se concentra, especificamente, sobre a discriminação interseccional. Com uma formulação distinta, Brah (2006) se atém às formas de constituição, contestação e (re)significação dos discursos sobre a diferença, destacando que a diferença pode estar associada à hierarquia e opressão e também à igualdade e diversidade.

Embora diferença e desigualdade estejam estreitamente conectadas, é possível notar que Creenshaw dedica maior atenção à discussão sobre a desigualdade, enquanto Brah aprofunda as reflexões sobre a diferença. Essas referências são importantes para o estudo da discriminação interseccional na educação superior, tema que já fora objeto de estudo em autores como Rosemberg e Andrade (2008), que propuseram o uso do conceito de não sincronia entre gênero e raça quando se trata de desigualdade racial na educação.

$\mathrm{Na}$ literatura sobre gênero e ciência no Brasil, muitos estudos tratam das assimetrias existentes entre homens e mulheres, mas são escassos aqueles que incluem nas análises questões sobre se, e como, mulheres brancas e negras são afetadas de maneiras distintas (cf. Minella, 2013). A partir do final da década de 1990, vários estudos têm descrito essas assimetrias, segundo o gênero, que se mantêm nas distintas áreas do conhecimento e carreiras científicas, muitos dos quais utilizando uma abordagem quantitativa (cf. Lombardi, 2008; Melo e Casemiro, 2004). Tais resultados se inserem em um contexto mais amplo, marcado pela segregação ocupacional por sexo no mercado de trabalho, um fenômeno que ocorre em escala global (cf. DeGraff e Anker, 2004).

Os estudos que descrevem as assimetrias no campo científico segundo o gênero têm mostrado também que é crescente a presença de mulheres em áreas do conhecimento e carreiras antes restritas aos homens. $\mathrm{O}$ aumento gradual da proporção de mulheres nessas áreas e carreiras tem sido referido como feminização, e ocorre de maneira mais rápida, por exemplo, nas ciências biológicas, enquanto se dá em ritmo mais lento nas ciências exatas 
(cf. Minella, 2013). Os estudos sobre as trajetórias das mulheres pioneiras, ou que estão inseridas atualmente em contextos que ainda são redutos masculinos, trazem evidências importantes para compreender os arranjos que contribuem para que as mulheres sejam excluídas de determinados espaços dentro do campo científico, e as estratégias que têm sido usadas para garantir a permanência das mulheres nesses espaços (cf. Vanin, 2008; Rago, 2007).

Argumentamos, no presente artigo, que é necessário reduzir a distância existente entre a linha de investigação sobre a desigualdade racial e as políticas de ação afirmativa no ensino superior, e a linha de investigação sobre as assimetrias entre homens e mulheres no campo da ciência. Conforme destacou Minella (2013), em contraste com a volumosa literatura sobre a desigualdade racial e políticas de ação afirmativa no ensino superior, são poucos os estudos que incluem a questão racial na discussão sobre gênero e ciência. De modo inverso, na literatura sobre desigualdade racial e políticas de ação afirmativa no ensino superior, poucos estudos têm tratado das disparidades entre negros e brancos, homens e mulheres, na categoria docente e nas carreiras acadêmicas e científicas.

A partir das referências teóricas existentes nessas duas linhas de investigação é que vamos abordar o caso da Universidade Federal da Bahia (UFBa), onde realizamos uma pesquisa para analisar as articulações entre distintas formas de desigualdade no contexto institucional, enfatizando as dimensões de raça e gênero. No âmbito dessa pesquisa, os conceitos de "raça" e "gênero" são entendidos como construções sociais que, historicamente, têm sido associados a formas de estigmatização e de desigualdade, bem como a processos de identificação. Além da revisão da literatura nos campos dos estudos sobre as relações raciais e de gênero, a parte empírica da pesquisa incluiu a sistematização de dados sobre a distribuição dos docentes, homens e mulheres, entre as três maiores áreas do conhecimento (ciências humanas, exatas e biológicas) e, internamente a cada uma delas, nos distintos cursos e departamentos. Embora esses resultados não sejam apresentados no presente artigo, a pesquisa aborda também a institucionalização de programas no campo dos estudos africanos e afro-brasileiros e dos estudos sobre mulheres e feminismos na UFBa.

A categorização dos docentes segundo o sexo foi realizada com base nas listas completas de nomes disponibilizadas pela instituição. Embora seja mais frequente o uso de dados sobre a categorização por sexo baseados na 
autoclassificação, a heteroclassificação permite que se tenha um resultado confiável, uma vez que a categorização por sexo se dá também de maneira externa, realizada por outras pessoas a partir do uso de convenções e normas que são definidas coletivamente. Não se trata, portanto, de processos de identificação, mas de categorização segundo o sexo. A heteroclassificação também é utilizada para a categorização segundo a cor, embora seja mais frequente o uso de autoclassificação. No caso da UFBa, a instituição não disponibilizava informações sobre a cor dos docentes, assim a categorização da cor com base em heteroclassificação não foi realizada. Outra fonte consultada foi o documento com a lista de cargos de direção ocupados por docentes e funcionários técnico-administrativos. Para complementar as informações, foram consultados, ainda, os currículos Lattes dos docentes, disponíveis no site do $\mathrm{CNPq}^{1}$.

Vale ressaltar que essa é a fase inicial de uma pesquisa mais ampla, cujo próximo passo incluirá a análise das experiências de mulheres que estão construindo carreiras acadêmicas nas distintas áreas do conhecimento descritas neste artigo, com base em entrevistas individuais que incluirão a autoclassificação por cor e sexo.

Nas duas próximas seções, apresentaremos uma breve revisão da literatura sobre a desigualdade racial e de gênero no ensino superior, e sobre as políticas de promoção da igualdade racial e de gênero que, direta ou indiretamente, tratam desse nível educacional. Na última seção, descreveremos a situação existente na UFBa em termos das assimetrias na distribuição dos docentes, homens e mulheres, nas três principais áreas do conhecimento. Nas conclusões, teceremos algumas considerações sobre as disparidades de raça e gênero e as políticas para combatê-las, no campo científico, e na educação superior.

\section{As assimetrias de raça e gênero no ensino superior}

Os estudos sobre a desigualdade racial na educação apresentam evidências de que, apesar da redução que ocorreu entre os anos 2000 e 2010, persistem as desvantagens dos pretos e pardos, quando comparados aos brancos. Por exemplo, o Relatório Anual das Desigualdades Raciais no Brasil: 2009-2010, utilizando dados de 1988, 1998 e 2008, da pré-escola à pós-graduação, demonstra que há significativa diferença separando pretos e pardos de

A saber, a pesquisa em questão recebeu apoio do CNPq. Os seguintes assistentes de pesquisa participaram da equipe: Edilene Santana dos Santos Silva, Simone dos Santos Borges e Yuri Santos de Brito 
brancos em quase todos os indicadores, e que as desvantagens dos pretos e pardos em relação aos brancos aumentam à medida que se elevam os níveis de escolaridade, chegando ao ápice no ensino superior e pós-graduação (cf. Paixão et al., 2010)².

Em relação à taxa de escolaridade líquida no ensino superior, os resultados mostraram que a disparidade existente entre pardos e pretos e brancos aumentou de 1988 (7,7\% contra 1,8\%) para 1998 (10,9\% contra 2\%). No período seguinte, 1998-2008, a diferença entre as taxas diminuiu, mas ainda continuou sendo 2,6 vezes maior para os brancos (20,5\%) quando comparados aos pretos e pardos (7,7\%). Em relação à pós-graduação, em 1988 , eram $88 \%$ de brancos e $7 \%$ de pretos e pardos; em 1998 , $85 \%$ e $13 \%$; em $2008,79 \%$ e cerca de $20 \%$.

Outro estudo recente compara os anos 2000 e 2010. Segundo os dados apresentados, considerando as pessoas com 15 anos ou mais por curso mais elevado concluído (mestrado/doutorado), em 2010 o percentual de brancos era de $80,7 \%$, enquanto o de negros era de $17,1 \%$; no ensino superior, o percentual de brancos era de $73,2 \%$ e o de negros era de $24,7 \%$; no ensino médio, a taxa de brancos era de $54,3 \%$ e a de negros, $44,2 \%$; e, apenas no ensino fundamental, a proporção entre brancos $(47,6 \%)$ e negros $(51,0 \%)$ era menor (cf. Silva, 2013) ${ }^{3}$.

Essas evidências confirmam que houve redução da desigualdade racial na educação nas últimas décadas, em especial a partir dos anos 2000, mas que persistem as desvantagens de pretos e pardos quando comparados aos brancos em termos de acesso a oportunidades educacionais: as desvantagens aumentam a partir do ensino médio e chegam ao máximo no ensino superior (graduação e pós-graduação).

Diferentemente do que ocorre no caso de negros e brancos, a comparação entre homens e mulheres mostra que as mulheres brasileiras, de todas as categorias de cor, têm apresentado melhores indicadores educacionais do que os homens, especialmente a partir do ensino médio. É digno de nota que houve crescimento dos anos médios de estudo, que, na faixa de 15 anos ou mais, passou de 4,5 para 7,4 anos entre 1988 e 2008 . No entanto, esse crescimento

\footnotetext{
Nesse relatório, as categorias de cor utilizadas são preto, pardo e branco, motivo que nos levou a mantê-las na apresentação dos dados.

Nesse estudo, as categorias de cor utilizadas são negro e branco e, por isso, mantemos a referência a essas categorias, e não foram apresentados os resultados segundo o sexo.
} 
foi mais acentuado entre mulheres em relação aos homens, do que entre os pretos e pardos comparados aos brancos. Em 1988, as mulheres dessa faixa etária já se igualavam aos homens em anos de estudo, ultrapassando-os a partir de 1998, resultado que se manteve em 2008. Nesse ano, as mulheres de 15 anos ou mais alcançaram 7,5 anos de estudo e os homens, 7,2 anos; no recorte entre os brancos, as mulheres alcançaram 8,3 anos e os homens, 8,2 anos; enquanto entre os pretos e pardos, as mulheres alcançaram 6,7 anos e os homens, 6,3 anos de estudo (cf. Paixão et al., 2010).

No caso do ensino superior, um estudo do IBGE (2012b), que traz a síntese dos indicadores sociais da população brasileira, confirma o que já vinha sendo mostrado nos estudos mencionados. A percentagem de pessoas de 18 a 24 anos, com 11 anos ou mais de estudo, em 2012, no Brasil, era 54,2\%, enquanto o percentual de mulheres era de $60,6 \%$ e o de homens, $47,9 \%$; o de brancos era $65,0 \%$ e o de pretos e pardos, $45,2 \%$. Essas taxas variam de acordo com a região do país, mas as disparidades entre homens e mulheres, e entre brancos e pretos/pardos, se mantêm. Os resultados do Censo da Educação Superior mais recentes (Mercadante, 2012) também mostram que as mulheres são maioria quando se consideram os ingressos por processo seletivo (45,4\% homens; $54,6 \%$ mulheres), as matrículas (44,5\% homens; $55,5 \%$ mulheres) e os concluintes (40,4\% homens; $59,6 \%$ mulheres).

Em síntese, diversos estudos comprovam que, no sistema de ensino superior brasileiro, o número de mulheres é maior que o de homens e que elas têm também obtido melhor aproveitamento escolar que eles nesse nível de ensino, e que essa tendência é mais acentuada nos estabelecimentos situados nas regiões Norte, Nordeste e Centro-Oeste, e entre pretos, pardos e indígenas quando comparados aos brancos (cf. Rosemberg e Andrade, 2008).

Esses resultados permitem afirmar que, considerando os indicadores educacionais citados anteriormente, a situação das mulheres não é correlata à situação dos negros. A inexistência de sincronia e paridade entre raça e gênero quando se trata da desigualdade na educação e, em especial, no ensino superior já foi destacada por Rosemberg e Andrade (2008) ao afirmarem que, no Brasil, a busca de compreensão simultânea das hierarquias de gênero, raça e classe tem se baseado, muitas vezes, em modelo paritário e cumulativo, esperando-se uma associação linear entre os eixos de desigualdade. Tal modelo associativo e paritário não dá conta, porém, da complexidade e das contradições observadas nas instituições educacionais 
onde as dinâmicas de gênero, raça, classe e idade não são redutíveis umas às outras, evidenciando, muitas vezes, um movimento não sincrônico, não cumulativo de desigualdades e resistência a elas.

No que diz respeito ao ensino superior, embora o número de mulheres na população de estudantes seja tão grande quanto, ou até mesmo maior, do que o de homens, a distribuição de homens e mulheres entre os diferentes cursos e carreiras não é equilibrada. Os estudantes do sexo masculino estão mais concentrados nos cursos da área de ciências exatas, enquanto as estudantes do sexo feminino estão mais concentradas em cursos das áreas de humanidades e ciências biológicas. Os resultados do Censo da Educação Superior (Mercadante, 2012) revelam que os cursos com maiores números de matrículas de graduação de estudantes do sexo feminino são: pedagogia, enfermagem, serviço social, gestão de pessoal e recursos humanos, psicologia, fisioterapia e farmácia. Enquanto os cursos com maiores números de matrículas de graduação de estudantes do sexo masculino são: engenharia civil, ciências da computação, engenharia de produção, engenharia mecânica, formação em professor de educação física, engenharia elétrica e gestão logística.

Essa distribuição desigual de estudantes homens e mulheres entre os cursos de graduação vai se refletir na distribuição dos professores universitários e pesquisadores entre os diferentes cursos, já que uma parcela daqueles que vão integrar a categoria docente se mantém em áreas próximas às dos cursos de graduação concluídos. A literatura sobre gênero e ciência apresenta fartas evidências de que, apesar dos melhores indicadores educacionais no ensino superior, as mulheres estão em desvantagem na carreira acadêmica e no campo científico, estando ausentes ou menos representadas nas posições de maior prestígio. No entanto, a literatura sobre raça e ciência não aponta resultados que permitam descrever a distribuição dos professores negros e brancos entre as áreas do conhecimento, cursos e carreiras acadêmicas.

O contraste entre a situação das mulheres e dos negros na educação nos leva a crer que a desigualdade de raça e gênero na educação, em especial no ensino superior, precisa ser analisada considerando os mais variados indicadores. Evidências como a taxa de escolaridade líquida no ensino superior e os anos de estudo são importantes, mas não são as únicas a serem utilizadas nas pesquisas. A análise da distribuição dos estudantes entre os diferentes cursos de graduação, por exemplo, permite evidenciar a desvantagem das mulheres em relação aos homens, que não foi percebida quando dados 
gerais sobre a média dos anos de estudo e sua distribuição nos distintos níveis educacionais foram considerados. E quando se trata da distribuição dos estudantes entre os diferentes cursos de graduação, notamos, como no caso da UFBa - que será abordado adiante -, similaridade entre a situação das mulheres e a dos negros, também sub-representados em determinados cursos superiores, principalmente naqueles considerados de maior prestígio.

\section{As políticas de promoção da igualdade de raça e gênero no ensino superior}

Os resultados das pesquisas que confirmam a existência de desvantagens dos estudantes negros quando comparados aos estudantes brancos, em especial no ensino superior, bem como a mobilização em prol da criação de cotas para negros nas universidades públicas brasileiras, foram importantes para que fossem criadas políticas de ação afirmativa na educação. Nessa área, essas políticas não se limitam à reserva de vagas nas universidades públicas, mas incluem ações para a formação de professores, inclusão de novos componentes nos currículos escolares, produção de material didático e paradidático, realização de cursos preparatórios para jovens negros e de baixa renda e financiamento dos estudos universitários. Atualmente, há no Brasil um conjunto de dispositivos legais que induzem a construção de uma política educacional visando afirmar a diversidade cultural e tornar realidade a educação para as relações étnico-raciais nas escolas ${ }^{4}$.

Acerca do ensino superior especificamente, nos anos 2000 começaram a ser criadas políticas de ação afirmativa nas instituições públicas desse nível de ensino, surgindo, posteriormente, uma iniciativa voltada às instituições privadas. Analisando brevemente os estudos que tratam dessas políticas, verificamos que tem crescido o interesse em examinar mais detalhadamente aspectos relacionados ao acesso dos estudantes aos diferentes cursos, o que inclui a sistematização de informações sociodemográficas sobre os ben-

Esse conjunto de leis inclui: i) a Lei no 10.639/2003, que estabeleceu a obrigatoriedade do ensino da história e cultura afro-brasileiras e africanas nas escolas públicas e privadas do ensino fundamental e médio; ii) o Parecer do CNE/CP no 03/2004, que aprovou as Diretrizes Curriculares Nacionais para Educação das Relações Étnico-Raciais e para o ensino de história e cultura afro-brasileiras e africanas; iii) a Resolução CNE/CP no 01/2004, que detalhou os direitos e as obrigações dos entes federados perante a implementação da Lei no 10.639/2003; iv) e a Lei no 11.645/2008, que modificou a Lei no 10.639/2003, estabelecendo a obrigatoriedade da inclusão no currículo oficial da rede de ensino da temática "História e Cultura Afro-Brasileira e Indígena" (cf. Brasil, 2005b). 
eficiários e seus familiares, e a análise de questões mais diretamente relacionadas à vida acadêmica, como rendimento escolar, taxas de conclusão, evasão e permanência dos estudantes (cf. Santos, 2013). No contexto pós-ações afirmativas no ensino superior brasileiro, a revisão da literatura comprova que as iniciativas existentes, tanto nas instituições públicas (federais e estaduais) como nas instituições privadas, têm-se concentrado no incentivo ao acesso e permanência de estudantes de renda familiar baixa, oriundos de escolas públicas, negros, indígenas e quilombolas (cf. Santos, 2012; Feres Jr. e Zoninsein, 2008; Brandão, 2007).

Esses estudos são importantes por documentar o processo de implementação das políticas de ação afirmativa nas Instituições de Ensino Superior (IES) que criaram esses programas. A existência de tais evidências baseadas em pesquisa empírica, dez anos após as primeiras universidades públicas terem criado tais políticas, nos deixa em melhores condições para ampliar a compreensão sobre as conquistas e as limitações das mesmas, bem como para levar adiante a agenda de pesquisa, de modo a destacar, por exemplo, a interface entre raça e gênero.

Em relação aos programas que criaram alterações no sistema de ingresso nas universidades públicas, a literatura recente mostra que há muita diversidade, como também existem diferenças em relação ao modo de implementação, aos segmentos beneficiados, aos modos de identificação e à proporção de reserva de vagas (cf. Brandão, 2007; César, 2007; Feres Jr. e Zoninsein, 2008; Bernardino e Galdino, 2004). Tal diversidade se deve, em parte, ao fato de que essas instituições tiveram autonomia para decidir sobre os seus processos seletivos e que, em cada uma delas, houve debate interno que conduziu à criação de um programa de ação afirmativa, considerado o mais apropriado e/ou o que contava com maior apoio da comunidade universitária.

O ingresso nas universidades públicas de um número maior de estudantes oriundos de escolas públicas, de famílias de renda baixa, negros, indígenas e quilombolas, foi motivo de preocupação para alguns críticos das políticas de ação afirmativa, que expressaram o temor de que haveria perda da qualidade de ensino nessas instituições. No entanto, pesquisas que analisaram os dados sobre o rendimento dos estudantes nos cursos, no período posterior à criação do sistema de reserva de vagas nas universidades públicas, têm reunido evidências convincentes de que inexistem diferenças sistemáticas de rendimento a favor dos estudantes que não são beneficiários das cotas (cf. Santos e Queiroz, 2013). 
O cenário descrito nos parágrafos anteriores tende a mudar bastante em razão da promulgação da Lei ${ }^{\circ} 12.711$, de 29 de agosto de 2012, que dispõe sobre o ingresso nas universidades federais e nas instituições federais de ensino técnico de nível médio. A chamada Lei das Cotas determina que as instituições federais de educação superior, vinculadas ao Ministério da Educação, reservem, em cada concurso seletivo para ingresso nos cursos de graduação, por curso e turno, no mínimo 50\% de suas vagas para estudantes que tenham cursado integralmente o ensino médio em escolas públicas. E, no preenchimento dessas vagas, $50 \%$ deverão ser reservados aos estudantes oriundos de famílias com renda igual ou inferior a 1,5 salário mínimo per capita. Além disso, as vagas serão preenchidas, por curso e turno, por autodeclarados pretos, pardos e indígenas, em proporção, no mínimo, igual a de pretos, pardos e indígenas na população da unidade da federação onde está instalada a instituição, segundo o último censo do IBGE.

É digno de nota que as políticas de ação afirmativa citadas não incluem a pós-graduação. Apenas recentemente o Ministério da Educação criou o Programa de Desenvolvimento Acadêmico Abdias Nascimento, que prevê a criação de cursos preparatórios para a seleção de mestrado e a oferta de bolsas para graduandos e doutorandos em universidades estrangeiras (cf. Brasil, 2014). No entanto, desde 2002, o Programa Internacional de Bolsas de Pós-Graduação da Fundação Ford (Programa IFP), desenvolvia atividades no Brasil e se apresentava como um programa de ação afirmativa na pós-graduação (Rosemberg e Andrade, 2008).

Em suma, quando se trata do ensino superior no país, foram os estudantes de graduação os principais beneficiários das políticas de ação afirmativa, as quais deixaram de considerar os professores e professoras que integram a categoria docente.

No que diz respeito a gênero, nos chama ainda a atenção inexistirem políticas de ação afirmativa nas IES públicas ou privadas visando combater a desigualdade de gênero. A única iniciativa governamental na área é o Programa Mulher e Ciência, lançado em 2005 pelo Conselho Nacional de Desenvolvimento Científico e Tecnológico (CNPq) em parceria com a Secretaria Especial de Políticas para as Mulheres (SPM), o Ministério da Ciência, Tecnologia e Inovação (MCTI), o Ministério da Educação (MEC), o Ministério da Saúde (MS) e a ONU Mulheres (cf. Brasil, 2005a). 


\section{As políticas de ação afirmativa na Universidade Federal da Bahia}

Assim como ocorreu em outras IES públicas brasileiras, na UFBa os estudos e o debate político se concentraram nas disparidades existentes na composição da população de estudantes de graduação, em termos de raça. Desde 2004, a UFBa alterou o processo seletivo para ingresso dos estudantes nos cursos de graduação, criando um sistema de cotas para candidatos que cursaram os três anos do ensino médio e mais um ano do ensino fundamental na rede pública de ensino. Além disso, foi estabelecido o percentual de $43 \%$ das vagas para todos os cursos, considerando a condição étnico-racial do estudante com a seguinte distribuição: $85 \%$ dessa reserva, ou seja, 36,5\% do total eram direcionadas para os autodeclarados pretos e pardos, e 15\% (6,5\%) aos autodeclarados não negros (brancos e/ou amarelos). Um percentual de $2 \%$ era destinado aos indiodescendentes, e uma reserva de duas vagas extras, em cada curso, para índios aldeados e estudantes oriundos de comunidades quilombolas (cf. Santos e Queiroz, 2013). Essa medida ocasionou mudanças significativas na composição da população de estudantes de graduação, provocando aumento proporcional de estudantes oriundos de escolas públicas e de estudantes negros e quilombolas.

No entanto, conforme demonstra Santos e Queiroz (2013), o impacto dessa medida se deu, principalmente, nos cursos considerados de alto prestígio, cujas vagas eram objeto de maior disputa: medicina, odontologia, psicologia, direito, bacharelado em ciências da computação, engenharia civil, elétrica, mecânica e química, administração e arquitetura. Nesses cursos, até 2004, a participação de estudantes do sistema público de ensino variava entre $10 \%$ e $25 \%$, e a participação de estudantes negros, quilombolas e indígenas também era reduzida, em comparação à de brancos. Porém, gênero não foi um critério considerado na medida.

Os dados atuais mostram que, nos cursos de alto prestígio analisados, a quantidade de estudantes do sexo masculino representa mais da metade dos selecionados nos últimos nove anos. Entre os anos de 2004 e 2012, Santos e Queiroz (2013) apontam que houve significativa mudança a partir do ano de 2008: o percentual de mulheres em 2007 era de 48,4\%; no ano seguinte, chegou a 52,2\%; aumentando a cada ano, até alcançar, em 2012, 55,9\%. No entanto, nos cursos de alto prestígio, o número de homens ultrapassa o de mulheres, o que, segundo os autores, se explica pela construção histórica de profissões exercidas por homens, mas também aponta para uma busca dessemelhante de carreiras de alto prestígio entre os gêneros. 
Em 2012, em razão da promulgação da Lei no 12.711, a UFBa fez alterações em seu programa de reserva de vagas. Mas, para além da reserva de vagas para estudantes de graduação, é importante considerar como, de maneira mais geral, a instituição tem se colocado no que diz respeito à criação e consolidação dos espaços institucionais voltados especificamente para a formação acadêmica e política em questões de raça/antirracismo e de gênero/feminismo. A UFBa possui uma Pró-Reitoria de Ações Afirmativas e Assistência Estudantil (PROAAE), mas esta dispõe de poucos recursos humanos e financeiros, e tem a sua atuação muito restrita às ações de caráter assistencial, com apenas uma iniciativa, o Programa Permanecer, visando ao apoio à permanência dos estudantes.

Em síntese, no caso da UFBa, como parte das políticas de ação afirmativa, nenhuma ação visando aos estudantes de pós-graduação, ou à categoria docente, foi implementada. As políticas existentes se restringem à promoção do acesso de estudantes de graduação, e consideram apenas os critérios de renda e étnico-raciais, inexistindo ações que tenham como beneficiárias as mulheres.

\section{As assimetrias de gênero na categoria docente na Universidade Federal da Bahia}

Tendo em vista a lacuna existente de estudos tratando da categoria docente na UFBa, é que nos propusemos a abordar o tema através de pesquisa empírica. A distribuição dos docentes, homens e mulheres, nas áreas de exatas (I), biológicas (II) e humanidades (III) da UFBa aqui apresentada deve ser situada em um contexto mais amplo, marcado pela heterogeneidade interna, característica da instituição como um todo, e de cada unidade universitária em particular, que se reflete na composição da categoria docente.

Inicialmente, é importante considerar, de maneira geral, a distribuição dos docentes, segundo o sexo e a classe, em todas as áreas do conhecimento nessa universidade. Os docentes estão divididos em cinco classes que, na ordem apresentada, vão do início ao final da carreira: auxiliar (graduação), assistente (mestrado), adjunto (doutorado), associado (doutorado) e titular (doutorado). Embora varie o percentual de docentes segundo as classes, homens e mulheres estão proporcionalmente distribuídos no interior de cada classe, com exceção da classe de titular, na qual as mulheres correspondem à metade dos docentes. Quando analisamos os dados gerais sobre a distribuição dos docentes apenas para as três maiores 
áreas do conhecimento tratadas nesta pesquisa - Área I (exatas), Área II (biológicas) e Área III (humanidades) -, os resultados são semelhantes, mostrando que há participação relativamente equilibrada: $51 \%$ de homens e $49 \%$ de mulheres ${ }^{5}$. No entanto, os resultados são muito distintos quando comparamos a distribuição dos docentes entre as grandes áreas do conhecimento selecionadas, e mais ainda quando verificamos de maneira detalhada como os docentes estão distribuídos entre as unidades de ensino que integram essas áreas, e entre os departamentos que compõem cada uma das unidades de ensino.

Vale ressaltar que nessas três áreas do conhecimento estão cerca de 85\% do total de docentes da UFBa. Os resultados mostram que em nenhuma delas se repete a distribuição equilibrada que foi mostrada quando os dados gerais foram considerados. Ou seja, em cada uma dessas áreas, varia a proporção entre homens e mulheres: nas Áreas I (exatas) e III (humanidades), os homens estão em maior número, resultado que se inverte apenas na Área II (biológicas). As assimetrias existentes entre homens e mulheres vão se tornando mais evidentes à medida que passamos da análise dos dados mais gerais para os mais específicos.

$\mathrm{Na}$ UFBa a Área I, ciências exatas, é formada pelas seguintes unidades de ensino: Escola Politécnica (165 docentes), Instituto de Física (72 docentes), Instituto de Matemática (133 docentes) e Instituto de Química (77 docentes). Ver Tabela 1.

Tabela 1 - Docentes homens e mulheres, por unidade universitária, da Área I (Abs. / \%)

\begin{tabular}{c|c|c|c}
\hline unidade universitária & homens & mulheres & total \\
\hline Escola Politécnica & $126(76,3 \%)$ & $39(23,6 \%)$ & $165(100 \%)$ \\
\hline Instituto de Matemática & $75(56,4 \%)$ & $58(43,6 \%)$ & $133(100 \%)$ \\
\hline Instituto de Química & $36(46,8 \%)$ & $41(53,2 \%)$ & $77(100 \%)$ \\
\hline Instituto de Física & $61(84,7 \%)$ & $11(15,3 \%)$ & $72(100 \%)$ \\
\hline total & $298(67 \%)$ & $149(33 \%)$ & $447(100 \%)$ \\
\hline
\end{tabular}

Fonte: Elaboração própria.

Esses resultados já mostram uma leve inversão da proporção entre homens e mulheres na população brasileira. Dados da PNAD (IBGE, 2012a), mostram que, em 2012, éramos 51,5\% de mulheres e 48,5\% de homens. 
A Área I é aquela que apresenta maior disparidade na proporção entre homens e mulheres docentes, estas em bem menor número, em um total de 447 docentes. A comparação entre as unidades de ensino que compõem a Área I mostra que no Instituto de Física e Escola Politécnica, onde estão os cursos de engenharia com maior contingente de estudantes e de professores, a presença masculina é maior. No Instituto de Matemática, os homens também são maioria, mas têm uma participação menor do que a média geral na Área I. O Instituto de Química é o único que difere dos demais, apresentando maior número de docentes mulheres.

Alguns estudos têm documentado as experiências das mulheres em áreas tidas tradicionalmente como "masculinas", como as engenharias (Cabral e Bazzo, 2005; Saraiva, 2005; Lombardi, 2005, 2006 e 2008), e em outras áreas mais recentes, como a química (Azevedo et al., 2004) e a informática (Rapkiewicz, 1998). Eles trazem destacadas a presença e atuação das mulheres nas ciências exatas e focalizam as relações entre homens e mulheres nos ambientes de trabalho.

Por exemplo, Faulkner (2006) comprovou que, na maioria das empresas de engenharia, são poucas as mulheres nos ambientes dominados pela presença masculina e nestes as mulheres engenheiras enfrentam o paradoxo da in/visibilidade, ou seja, são tão visíveis como mulheres que muitas vezes são invisíveis como engenheiras. Nesse contexto, mesmo engenheiras experientes precisam enfatizar as suas credenciais na engenharia a cada encontro com um novo colega, algo que não acontece com engenheiros em situação semelhante. O paradoxo da in/visibilidade coloca as mulheres diante de uma dupla pressão: por um lado, elas são chamadas a se integrar, no sentido de se adaptar às regras tácitas de um ambiente masculinizado, e, por outro lado, são cobradas a não "perder a feminilidade".

A Área II (ciências biológicas) é a maior da UFBa, entre as três selecionadas na pesquisa, com um total de 910 docentes, e nela estão as seguintes unidades de ensino: Escola de Enfermagem (87 docentes), Escola de Nutrição (69 docentes), Faculdade de Farmácia (57 docentes), Faculdade de Odontologia (94 docentes), Instituto de Biologia (67 docentes), Instituto de Ciências da Saúde (148 docentes), Instituto de Saúde Coletiva (35 docentes), Escola de Medicina Veterinária e Zootecnia (79 docentes) e Faculdade de Medicina (274 docentes). Ver Tabela 2. 
Tabela 2 - Docentes homens e mulheres, por unidade universitária, da Área II (Abs. / \%)

\begin{tabular}{c|c|c|c}
\hline unidade universitária & homens & mulheres & total \\
\hline Faculdade de Medicina & $151(55 \%)$ & $123(45 \%)$ & 274 \\
\hline Instituto de Ciências da Saúde & $59(40 \%)$ & $89(60 \%)$ & 148 \\
\hline Faculdade de Odontologia & $35(37 \%)$ & $59(63 \%)$ & 94 \\
\hline Escola de Enfermagem & $7(8 \%)$ & $80(92 \%)$ & 87 \\
\hline Escola de Medicina Veterinária e Zootecnia & $42(53 \%)$ & $37(47 \%)$ & 79 \\
\hline Escola de Nutrição & $11(16 \%)$ & $58(84 \%)$ & 69 \\
\hline Instituto de Biologia & $27(40 \%)$ & $40(60 \%)$ & 67 \\
\hline Faculdade de Farmácia & $21(37 \%)$ & $36(63 \%)$ & 57 \\
\hline Instituto de Saúde Coletiva & $10(28,6 \%)$ & $25(71,4 \%)$ & 35 \\
\hline total & $363(39,9 \%)$ & $547(60,1 \%)$ & 910 \\
\hline
\end{tabular}

Fonte: Elaboração própria.

Na maioria das unidades de ensino da Área II, há mais mulheres docentes do que homens, e a Escola de Enfermagem é a unidade de ensino onde há predominância de mulheres. No entanto, isto não ocorre na Faculdade de Medicina Veterinária e Zootecnia e na Faculdade de Medicina. Esta última, a maior em termos numéricos, concentra cerca de 30\% do total de docentes dessa Área. A distribuição dos docentes entre os nove departamentos que compõem a Faculdade de Medicina também não é equilibrada: existem três departamentos com maioria de homens, um departamento exclusivamente masculino e cinco departamentos com maioria de mulheres.

A baixa participação das mulheres na medicina tem sido documentada (Melo e Casemiro, 2004) ${ }^{6}$, assim como a atuação das mulheres que foram pioneiras nessa área (Rago, 2007; Vanin, 2008), e as dificuldades que as mulheres enfrentam para a construção da carreira profissional nesse campo (cf. Santos, 2010).

A Área III é formada por dez unidades de ensino diferentes, com um total de 588 docentes: Instituto de Psicologia e Serviço Social (47 docentes), Faculdade de Direito (95 docentes), Escola de Administração (56 docentes), Instituto de Ciências da Informação (25 docentes), Faculdade de Educação

\footnotetext{
Segundo Melo e Casemiro (2004), a Academia Nacional de Medicina só teve cinco mulheres eleitas para membro titular ao longo de 173 anos da instituição, enquanto existiram 612 sócios titulares do sexo masculino. No caso da Academia Brasileira de Ciências, as mulheres representavam 9,8\% do total de 571 sócios.
} 
(88 docentes), Faculdade de Comunicação (35 docentes), Faculdade de Ciências Contábeis (28 docentes), Faculdade de Ciências Econômicas (37 docentes), Faculdade de Filosofia e Ciências Humanas (108 docentes) e Instituto de Geociências (69 docentes). Ver Tabela 3.

Tabela 3 - Docentes homens e mulheres, por unidade universitária, da Área III (Abs. / \%)

\begin{tabular}{c|c|c|c}
\hline unidade universitária & homens & mulheres & total \\
\hline Faculdade de Filosofia e Ciências Humanas & $54(50 \%)$ & $54(50 \%)$ & 108 \\
\hline Faculdade de Direito & $71(75 \%)$ & $24(25 \%)$ & 95 \\
\hline Faculdade de Educação & $35(40 \%)$ & $53(60 \%)$ & 88 \\
\hline Instituto de Geociências & $51(74 \%)$ & $18(26 \%)$ & 69 \\
\hline Escola de Administração & $35(63 \%)$ & $21(37 \%)$ & 56 \\
\hline Instituto de Psicologia e Serviço Social & $10(21 \%)$ & $37(79 \%)$ & 47 \\
\hline Faculdade de Ciências Econômicas & $32(86 \%)$ & $5(14 \%)$ & 37 \\
\hline Faculdade de Comunicação & $24(69 \%)$ & $11(31 \%)$ & 35 \\
\hline Faculdade de Ciências Contábeis & $19(68 \%)$ & $9(32 \%)$ & 28 \\
\hline Instituto de Ciências da Informação & $6(24 \%)$ & $19(76 \%)$ & 25 \\
\hline total & $337(57,3 \%)$ & $251(42,7 \%)$ & 588 \\
\hline
\end{tabular}

Fonte: Elaboração própria.

Os resultados revelam que, em três das unidades de ensino que integram a Área III, as mulheres são maioria - Instituto de Psicologia e Serviço Social, Instituto de Ciências da Informação e Faculdade de Educação -, enquanto em seis delas os homens são maioria: Faculdade de Ciências Econômicas, Faculdade de Direito, Instituto de Geociências, Faculdade de Ciências Contábeis, Faculdade de Comunicação, e Escola de Administração. Apenas na Faculdade de Filosofia e Ciências Humanas existe uma distribuição equilibrada de docentes segundo o sexo.

As Faculdades de Direito, Economia e Escola de Administração concentravam grande parte dos docentes que ocupavam cargos na administração pública, enquanto a Faculdade de Educação concentrava docentes que ocupavam postos de prestígio dentro da própria universidade. Em ambos os casos, havia uma predominância masculina. Para citar alguns exemplos, na Faculdade de Direito havia dez docentes juízes contra duas docentes juízas e sete promotores e procuradores de justiça contra duas promotoras ou procuradoras. $\mathrm{Na}$ administração pública, havia sete homens ocupantes, ou 
antigos ocupantes, de cargos de assessoria, presidência de empresa pública, secretaria ou superintendência, tanto no governo estadual como no federal, contra apenas duas mulheres, uma ex-secretária estadual e outra vice-prefeita de Salvador. Nos postos de prestígio dentro da universidade, havia quatro mulheres desempenhando funções relevantes: coordenação e presidência de comissões permanentes na administração central, presidência da associação de professores e a própria reitora. Por outro lado, havia apenas um homem, um pró-reitor. No entanto, cabe destacar novamente que, à exceção da própria reitora, o cargo de maior prestígio era o de diretor de unidade, onde havia, no momento da pesquisa, exclusividade masculina na Área III ${ }^{7}$.

Alguns estudos têm documentado a situação das mulheres em carreiras de prestígio, como medicina, direito, engenharia e arquitetura (cf. Bruschini e Lombardi, 1999), ou em determinadas instituições de ensino superior (Velho e Léon, 1998), e os resultados confirmam que a participação feminina diminui nas carreiras de maior status e nas posições mais elevadas da hierarquia ocupacional, enquanto a participação masculina cresce nas ocupações de maior prestígio e mais bem remuneradas. Outras pesquisas que analisaram a distribuição de bolsas de produtividade por sexo, entre as distintas áreas do conhecimento, confirmam haver menos bolsistas mulheres do que homens, diminuindo proporcionalmente a participação das mulheres quanto mais altos os estratos da escala utilizada pelo CNPq (cf. Melo, 2010; Melo e Lastres, 2006; Leta, 2003) $)^{8}$.

As evidências de que as mulheres estão menos presentes nas áreas de maior prestígio, que remuneram melhor, ocupando em menor proporção os cargos de direção, e sendo menos contempladas com bolsas de produtividade, indicam que as chances de sucesso e ascensão na carreira acadêmica e científica são menores para as mulheres (cf. Leta, 2003).

O caso da Faculdade de Medicina da UFBa mostra que é imprescindível considerar as características específicas das várias carreiras que integram as

No conjunto de docentes que ocupam, ou ocuparam, posições de prestígio, aí incluídas as já citadas e também outros casos, como de presidência de associações de pesquisa, representação em conselhos superiores, coordenação de cursos de graduação e pós-graduação e outros vários, foram identificados 76 docentes, sendo 23 mulheres (30\%) e 53 homens (70\%).

8 Melo (2010) analisou o sistema de concessão de bolsas de pesquisa do CNPq, no período de 2001 e 2008, e concluiu que, em relação às bolsas de produtividade, o percentual de homens (22\%) era o dobro do de mulheres (11\%), e que os postos mais elevados da hierarquia acadêmica continuavam sendo ocupados majoritariamente por homens. 
grandes áreas do conhecimento. Algo semelhante pode ser notado na área de ciências humanas, onde, na Faculdade de Direito da UFBa, por exemplo, os homens são maioria. No Brasil, as profissões de médico e de advogado têm alto prestígio, são tradicionais, e a imagem dos chamados "doutores" que atuam nessas áreas, até recentemente, era associada a homens, de classes médias e altas, e brancos.

A distribuição de docentes, homens e mulheres, em três áreas distintas do conhecimento da UFBa aqui apresentada é uma aproximação do que se encontrava no momento em que o levantamento foi realizado e, em linhas gerais, reitera o que tem sido mostrado em inúmeros estudos sobre o tema. Ou seja, quando se trata de carreiras acadêmicas, em especial em instituições de ensino superior públicas, os homens são maioria nos cursos considerados de maior prestígio e mais tradicionais, independente da área do conhecimento, enquanto as mulheres estão mais concentradas nos cursos associados ao cuidar, de menor prestígio e menos tradicionais. No entanto, a participação feminina pode ser comprovada mesmo em cursos da área de ciências exatas que, no passado, eram redutos exclusivamente masculinos.

\section{Conclusões}

As evidências produzidas na pesquisa realizada na UFBa convidam a refletir sobre a desigualdade racial e de gênero, e as políticas para combatê-las, nas Instituições de Ensino Superior (IES). Inicialmente, foi visto que, considerando alguns indicadores educacionais, a situação das mulheres não era correlata à situação dos negros, inexistindo sincronia e paridade entre raça e gênero quando se trata da desigualdade na educação e, em especial, no ensino superior. No entanto, quando a distribuição dos estudantes entre os diferentes cursos foi considerada, observou-se uma relativa aproximação entre a situação de ambos, no sentido de que as vantagens das mulheres quando comparadas aos homens deixavam de existir, situação similar à dos negros quando comparados aos brancos.

Ao deslocar a atenção para a categoria docente, foi visto que não havia uma distribuição equilibrada dos docentes segundo o sexo, de maneira que as mulheres estavam concentradas em algumas unidades de ensino, cursos e departamentos, e ausentes dos cargos de direção e de prestígio, seja dentro ou fora da UFBa. A assimetria na distribuição dos docentes, homens e mulheres, contribui para a manutenção de estereótipos e categorizações 
baseados em sexo, e para a menor frequência da convivência entre eles, o que impede, ou dificulta, haver mudanças no cenário descrito neste artigo (cf. Goffman, 1977). Por exemplo, nos cursos da área de saúde é mais difícil romper as associações entre a representação do médico como homem e da enfermeira como mulher. Por outro lado, é possível esperar que a presença de mulheres em áreas antes exclusivamente masculinas contribua para alterar tais estereótipos e categorizações.

Como o levantamento sobre a distribuição dos docentes segundo a cor na UFBa não foi realizado, é impossível estabelecer um contraste e explorar as aproximações e discrepâncias existentes em termos de gênero e raça. No entanto, é importante considerar que a participação de homens e mulheres, assim como de negros e brancos, nas carreiras acadêmicas deve ser analisada não apenas em termos quantitativos, com base nos números existentes em distintas áreas do conhecimento, unidades de ensino e cursos.

Para aprofundar a compreensão sobre o significado da participação de homens e mulheres, e de negros e brancos, nas carreiras acadêmicas e científicas, é importante analisar as suas experiências, destacando aspectos subjetivos e simbólicos. Como foi visto anteriormente, já existem muitos estudos que documentam as experiências das mulheres na linha de investigação sobre gênero e ciência. Estudos recentes sobre as experiências de docentes negros na área acadêmica estão reduzindo a lacuna existente no que diz respeito às reflexões sobre raça e ciência e permitirão aprofundar a compreensão sobre o tema (cf. Cruz, 2009; Gomes, 2004; Santos, 2007; Laborne, 2009). Nesse sentido, um aspecto que merece ser considerado é a existência de estereótipos que desqualificam indivíduos negros como docentes e pesquisadores, deixando-os em desvantagem em relação aos pares quando se trata de competição pela autoridade científica (cf. Hooks, 1995).

A nosso ver, é importante documentar os processos através dos quais instituições como as universidades contribuem para reproduzir, ou reduzir, desigualdades duráveis, como as de gênero e raça. Nesse sentido, a UFBa destaca-se pela criação, em 2004, de uma política de ação afirmativa voltada ao acesso de estudantes de graduação, que deverá seguir as orientações da chamada Lei de Cotas (de 2012), o que representa compromisso da instituição com a promoção da igualdade racial. No entanto, os professores não foram contemplados até o momento na política existente, e não há uma 
política correlata, tratando de estudantes e/ou de professores, voltada para a promoção da igualdade de gênero.

As reflexões de Ridgeway (1997) são úteis para analisarmos o cenário pós-ações afirmativas em que novos arranjos institucionais foram criados nas IES, e estão sendo revistos a partir da promulgação da Lei de Cotas. Segundo a autora, para explicar como a desigualdade de gênero persiste mesmo quando mudanças estruturais mais amplas estão em curso, é preciso levar em conta que, apesar da criação de novos arranjos institucionais, a desigualdade pode ser reescrita através da mediação da desigualdade de gênero por processos interacionais que não são objeto de reflexão e são aceitos como algo dado. As conclusões a que a autora chega tratando da desigualdade de gênero são úteis para analisar a desigualdade racial nas instituições.

Os resultados sobre a interface entre as disparidades de gênero e raça no ensino superior devem ser levados em consideração na discussão sobre as políticas de promoção da igualdade no ensino superior. Foi visto que as políticas de ação afirmativa nas IES se limitaram muito à reserva de vagas para estudantes de graduação, não incluindo ações que tivessem os estudantes de pós-graduação, ou os professores como beneficiários. Assim como foi visto que faltam iniciativas que focalizem as disparidades de gênero e que alcancem as instituições como um todo. As evidências apresentadas no caso da UFBa ilustram bem esse cenário nacional.

Levar adiante a análise sobre a interface entre as desigualdades de gênero e raça nas IES brasileiras coloca diante de nós uma dupla tarefa. Por um lado, é preciso dispor de informações sobre a classificação segundo a cor dos docentes, para que se possa saber como estes se distribuem entre os distintos cursos e departamentos, e, em paralelo, discutir formas de inclusão da categoria docente no debate sobre as políticas de ação afirmativa com recorte étnico-racial. Por outro lado, é preciso analisar trajetórias, e focalizar as experiências das mulheres e dos negros, usando metodologia qualitativa, para entender melhor os processos interacionais.

\section{Referências bibliográficas}

AZEVEDO, Nara et al. (2004). "Gênero e ciência: a carreira científica de Aída Hassón-Voloch". Cadernos Pagu, n. 23, p. 356-87.

BARRETO, Paula Cristina da Silva (2008). Múltiplas vozes. Racismo e 
anti-racismo na perspectiva de universitários de São Paulo. Salvador: Editora da UFBa.

BERNARDINO, Joaze \& GALDINO, Daniela (orgs.) (2004). Levando a raça a sério: ação afirmativa e universidade. Rio de Janeiro: DP\&A. BRAH, Avtar (2006). “Diferença, diversidade, diferenciação”. Cadernos Pagu, n. 26, p. 329-65.

BRANDÃO, André Augusto (org.) (2007). Cotas raciais no Brasil: a primeira avaliação. Rio de Janeiro: DP\&A.

BRASIL. Ministério da Ciência, Tecnologia e Inovação (MCTI). Conselho Nacional de Desenvolvimento Científico e Tecnológico (CNPq) (2005a). Programa Mulher e Ciência. Disponível em: <http://www.cnpq.br/web/ guest/mulher-e-ciencia>. Acesso em: 5 mar. 2015.

BRASIL. Ministério da Educação. Secretaria de Educação Continuada, Alfabetização e Diversidade e Inclusão (MEC/Secad) (2005b). Educação anti-racista: caminhos abertos pela Lei Federal $n^{\circ}$ 10.639/03. Brasília: MEC/Secad.

BRASIL. Ministério da Educação. Fundação Capes (2014). Programa de Desenvolvimento Acadêmico Abdias Nascimento para Projetos Conjuntos de Pesquisa entre Instituições Brasileiras e Estrangeiras com Modalidades de Graduação Sanduíche e Doutorado Sanduíche. Disponível em: <http:// www.capes.gov.br/cooperacao-internacional/multinacional/programa-abdias-nascimento-projetos-conjuntos-de-pesquisa>. Acesso em: 30 set. 2014.

BRUSCHINI, Cristina \& LOMBARDI, Maria Rosa (1999). "Médicas, arquitetas, advogadas e engenheiras: mulheres em carreiras de prestígio". Revista Estudos Feministas, v. 7, n. 1, p. 9-24.

CABRAL, Carla \& BAZZO, Walter Antonio (2005). "As mulheres nas escolas de engenharia brasileiras: história, educação e futuro". Revista de Ensino de Engenharia, v. 24, n. 1, p. 3-9.

CARVALHO, José Jorge de (2005-2006). “O confinamento racial do mundo acadêmico brasileiro”. Revista USP, n. 68, p. 88-103.

CESAR, Raquel C. Lenz (2007). "Políticas de inclusão no ensino superior brasileiro: um acerto de contas e de legitimidade”, em BRANDÃO, André Augusto (org.). Cotas raciais no Brasil: a primeira avaliação. Rio de Janeiro: DP\&A. p. 13-34. 
CHARÃO, Cristina (2011). "O longo combate às desigualdades raciais". Desenvolvimento, v. 8, n. 70, p. 22-31.

CRENSHAW, Kimberlé (2002). "Documento para o Encontro de Especialistas em Aspectos da Discriminação Racial Relativos ao Gênero”. Estudos Feministas, v. 10, n. 1, p. 171-88.

CRUZ, Ricardo Alexandre da (2009). Negro e educação: as trajetórias e estratégias de dois professores da Faculdade de Direito de São Paulo. Dissertação (mestrado) em Educação, História, Política e Sociedade. São Paulo: PUC. DEGRAFF, D. F. \& ANKER, R. (2004). "Gênero, mercados de trabalho e o trabalho das mulheres”. Campinas: Associação Brasileira de Estudos de População (Abep) (Demographicas, v. 2). p. 163-97. Disponível em: <http://www.abep.nepo.unicamp.br/docs/outraspub/Demographicas2/ demographicas2artigo4_163a197.pdf >. Acesso em: 4 mar. 2015.

FAULKNER, Wendy (2006). "Genders in/of Engineering. A research report". Edinburgh: The University of The University of Edinburgh; Economic and Social Research Council (ESRC), March. Disponível em: <http://www.sps.ed.ac.uk/__data/assets/pdf_file/0020/4862/ FaulknerGendersinEngineeringreport.pdf $>$. Acesso em: 12 mar. 2015.

FERES JR., J. \& ZONINSEIN, J. (orgs.) (2008). Ação afirmativa e universidade: experiências nacionais comparadas. Brasília: Editora da UnB.

GOFFMAN, Ervin (1977). “The arrangement between the sexes". Theory and Society, v. 4, n. 3, p. 301-31.

GOMES, Verônica Maria da Silva (2004). Indivíduos "Fora de Lugar": o caso dos(as) docentes negros(as) nas relações de trabalho na Universidade de Brasília. Dissertação (mestrado) em Sociologia. Brasília: Universidade de Brasília.

HOOKS, Bell (1995). "Intelectuais negras". Revista Estudos Feministas, v. 3, n. 2, p. 454-78.

IBGE - Instituto Brasileiro de Geografia e Estatística (2012a). Pesquisa Nacional por Amostra de Domicílios (PNAD). Síntese de Indicadores 2012. Rio de Janeiro: IBGE.

(2012b). Sistema de Indicadores Sociais: uma análise das condições de vida da população brasileira, 2012. Rio de Janeiro: IBGE (Série Estudos e pesquisas. Informação demográfica e socioeconômica). 
LABORNE, Ana Amélia de Paula (2009). “Trajetórias de docentes do ensino superior: ações afirmativas no contexto da Universidade Federal de Minas Gerais", em AGUIAR, M. A. da S. (org.). Educação e diversidade: estudos e pesquisa. Recife: Gráfica J. Luiz Vasconcelos Editora. v. I e II.

LETA, Jacqueline (2003). "As mulheres na ciência brasileira: crescimento, contrastes e um perfil de sucesso”. Estudos Avançados, v. 17, n. 49, p. 271-84.

LOMBARDI, Maria Rosa (2005). Perseverança e resistência: a engenharia como profissão feminina. Tese (doutorado), Faculdade de Educação. Campinas: Unicamp.

(2006). "A engenheira brasileira contemporânea e a contribuição das mulheres nas mudanças recentes no campo profissional”. Revista Tecnologia e Sociedade, n. 2. Disponível em: <www.ppgte.ct.utfpr.edu. br/>. Acesso em: 30 set. 2014.

(2008). As mulheres nas Forças Armadas brasileiras: a Marinha do Brasil. São Paulo: Fundação Carlos Chagas.

MELO, Hildete Pereira de (2010). "Um olhar de gênero sobre o sistema de concessão de Bolsas de Pesquisa no CNPq - 2001/2008”. In: BRASIL. Presidência da República. Secretaria Especial de Políticas para as Mulheres. Pensando Gênero e Ciência. Encontro Nacional de Núcleos e Grupos de Pesquisa - 2009, 2010. Brasília.

MELO, Hildete Pereira de \& CASEMIRO, Maria Carolina Pereira (2004). "A ciência no feminino: uma análise da Academia Nacional de Medicina e da Academia Brasileira de Ciência”. Revista Rio de Janeiro, n. 11, p. 117-34.

MELO, Hildete Pereira de \& LASTRES, Helena Maria Martins (2006). "Ciência e tecnologia numa perspectiva de gênero: o caso do CNPq", em SANTOS, Lucy Woelner dos et al. Ciência, tecnologia e gênero. Desvelando o feminino na construção do conhecimento. Londrina: Iapar.

MERCADANTE, Aloízio (2012). Censo da Educação Superior 2012. Brasília: Ministério da Educação.

MINELLA, Luzinete Simões (2013). “Temáticas prioritárias no campo de gênero e ciências no Brasil: raça/etnia, uma lacuna?". Cadernos Pagu, n. 40, p. $95-140$.

PAIXÃO, Marcelo; ROSSETTO, Irene; MONTOVANELE, Fabiana \& CARVANO, Luiz M. (orgs.) (2010). Relatório Anual das Desigualdades Raciais no Brasil: 2009-2010. Rio de Janeiro: Garamond.

PISCITELLI, Adriana (2008). "Interseccionalidades, categorias de articulação 
e experiências de migrantes brasileiras". Sociedade e Cultura, v. 11, n. 2, p. 263-74.

RAGO, Elisabeth Juliska (2007). Outras falas: feminismo e medicina na Bahia (1836-1931). São Paulo: Annablume; Fapesp.

RAPKIEWICZ, Clevi Elena (1998). “Informática: domínio masculino?”. Cadernos Pagu, n. 10, p. 169-200.

RIDGEWAY, Cecilia L. (1997). "Interaction and the conservation of gender inequality: considering employment”. American Sociological Review, n. 62, p. 218-35.

ROSEMBERG, Fúlvia \& ANDRADE, Leandro Feitosa (2008). “Ação afirmativa no ensino superior brasileiro: a tensão entre raça/etnia e gênero". Cadernos Pagu, n. 31, p. 419-37.

SANTOS, Jocélio Teles dos (org.) (2012). Cotas nas universidades brasileiras: análise dos processos de decisão. Salvador: Centro de Estudos Afro-Orientais.

(2013). O impacto das cotas nas universidades públicas brasileiras (2004-2012). Salvador: Centro de Estudos Afro-Orientais.

SANTOS, Jocélio Teles dos \& QUEIROZ, Delcele Mascarenhas (2013). "O impacto das cotas na Universidade Federal da Bahia (2004-2012)", em SANTOS, Jocélio Teles dos (org.). O impacto das cotas nas universidades públicas brasileiras (2004-2012). Salvador: Centro de Estudos Afro-Orientais. p. 37-65.

SANTOS, Tania Steren dos (2010). Carreira profissional e gênero: trajetória de homens e mulheres na medicina. Porto Alegre: Editora da UFRGS.

SANTOS, Tereza (2007). Trajetórias de professores universitários negros: a voz e a vida dos que trilharam. Cuiabá: Editora da UFMT.

SARAIVA, Karla (2005). "Fabricando identidades femininas em Escolas de Engenharia". Cadernos de Gênero e Tecnologia, n. 4, Curitiba, Editora do Cefet.

SILVA, Tatiana Dias (2013). "Panorama social da população negra", em SILVA, Tatiana Dias \& GOES, Fernanda Lira (orgs.). Igualdade racial no Brasil: reflexões no Ano Internacional dos Afrodescendentes. Brasília: Ipea. p. 13-28. Disponível em: <http://www.ipea.gov.br/igualdaderacial/ images/stories/pdf/livro_igualdade_racialbrasil01.pdf $>$. Acesso em: 4 mar. 2015.

VANIN, Iole Macedo (2008). As damas de branco na biomedicina baiana 
(1879-1949): médicas, famacêuticas e odontólogas. Tese (doutorado) em História. Salvador: Universidade Federal da Bahia.

VELHO, Léa \& LEON, Helena (1998). “A construção social da produção científica por mulheres”. Cadernos Pagu, n. 10, p. 309-44.

\section{Resumo}

$\mathrm{O}$ artigo trata da interação entre as dimensões de gênero e raça das desigualdades e as políticas de ação afirmativa no ensino superior. Na primeira sessão, apresenta uma síntese dos resultados de pesquisas sobre a situação de negros e brancos, e homens e mulheres, no ensino superior. Em seguida, comenta sobre as políticas de ação afirmativa criadas no Brasil, principalmente, nesse nível educacional. Na seção seguinte, apresenta as evidências produzidas através de pesquisa empírica realizada sobre a distribuição de homens e mulheres na categoria docente da Universidade Federal da Bahia. Nas conclusões, são tecidas considerações sobre a interface $\mathrm{e}$ as tensões existentes entre as dimensões raciais e de gênero das desigualdades, tratando, especificamente, das instituições brasileiras de ensino superior.

Palavras-chave: desigualdade, ação afirmativa, gênero, raça, ensino superior.

\section{Abstract}

The article approaches the interaction between the dimensions of gender and racial inequality and affirmative action policies in higher education. In the first session, it presents a summary of research findings on the situation of blacks and whites, and men and women, in higher education. Then it comments on affirmative action policies created in Brazil mainly in higher education. The next section presents the evidence produced by empirical research about the distribution of men and women among professors of the Federal University of Bahia. In its conclusions, it presents considerations about the interface and the tensions between racial and gender dimensions of inequality, specifically the Brazilian higher education institutions.

Keywords: inequality, affirmative action, gender, race, higher education.

Recebido em 30 de setembro de 2014.

Aprovado em 9 de fevereiro de 2015. 